\title{
MEDICAL KNOWLEDGE AND STATISTICAL METHODS IN EARLY NINETEENTH-CENTURY FRANCE
}

\author{
by \\ TERENCE D. MURPHY*
}

\section{INTRODUCTION}

In eighteenth-century France the outstanding achievements in the physical and natural sciences contrasted sharply with the limited advances of the medical arts. A growing confidence in the ability to manipulate the material world only increased frustration at the unsteady progress in medicine; the complex equilibrium between the human organism and the milieu eluded precise scrutiny, and frequently contemporary theory failed to guide practitioners in the successful treatment of numerous illnesses. Confronting this difficulty, physicians reaffirmed their commitment to heal the sick and to protect the healthy. Yet this heightened attention to traditional ends did not silence critics who exposed the tenuous qualities of medical practice, nor did it reassure younger practitioners who questioned the adequacy of medical knowledge. Perhaps success in so many other areas of human endeavour raised their expectations beyond legitimate limits.

Even apart from individual reactions to particular cases, a more public and more general problem remained. Since mid-century, philosophers had aspired to place the study of man at the centre of their naturalistic world view, an ambition which saw progress in medical science as an integral part of a larger, long-term project. Convinced of the validity of their optimistic perspective on the future, thoughtful physicians paused to examine the groundings of medical science, its methods, and the degree of certitude appropriate to medical judgments. From Pierre Cabanis to Claude Bernard, physicians undertook this re-evaluation in the context of medicine's relationship to both the moral and physical sciences and, most importantly, against the background of Enlightenment ideology. Human concerns, stripped of any theological pretensions, occupied the centre of this new world view. The elimination of poverty, the instauration of constitutional government, and the propagation of civil virtue were grandiose ambitions nourished by a faith in the community's ability to redefine social goals in national and democratic terms rather than according to the needs of any privileged group or individual. Underlying these goals was the fundamental truth that perceptive and well-trained men could understand the complexity of economic motivation and social choice, a trust founded upon the belief that a century of progress in the rational and experimental sciences could translate into a similar revolution in moral and civic life.

\footnotetext{
* Terence D. Murphy, Ph.D., American College in Paris, 31 Avenue Bosquet, 75007 Paris, France.
} 


\section{Terence D. Murphy}

Exactly how such a transfer was to take place perplexed reformers, but several currents of contemporary thought provided strong motivation for the attempt. D'Alembert's belief in the essential unity of knowledge, for example, permeated Enlightenment writing and heightened confidence in analytical methods, so much so that social reformers and even doctors considered their use to resolve problems of political and medical choice. The calculus of probabilities, statistical analysis, or more simple numerical methods enjoyed favour among diverse practitioners. Pinel praised their use in evaluating the treatment of the mentally disturbed, Villermé turned to them for an analysis of public health problems, and Louis valued their help in therapeutics. To be sure, the dubious legacy of earlier eighteenth-century attempts to use quantitative methods discouraged widespread or rapid adoption of numerical analysis. While not totally deficient, these earlier approaches, such as Pitcairne's, were hardly fruitful or encouraging examples for his successors. More pointedly, certain critics of numerical techniques (and they were many) affirmed the unique nature of the doctor's personal intervention in the life of an ailing patient, an act which necessarily precluded any application of statistical analysis.

Writing just before the French Revolution, Cabanis first formalized the reaction to quantitative techniques. Yet, his debt to Condillac and sensationalist psychology demonstrated his allegiance to another tenet of Enlightenment thought, the firm integration of the study of man into a secular and naturalistic world view. A first step in this process was the interpretation of intellectual or psychic processes in material terms or, put differently, the affirmation of a link between consciousness and material existence. This reversal of the Cartesian formula allowed Cabanis to dramatize the quality of the doctor-patient relationship and de-emphasize quantitative methods which might neutralize the personal nature of the medical act. Again, his attachment to the specific nature of medical practice ruled out any formal alliance with the natural sciences and justified claims for a criterion of medical knowledge independent of any formal standards established in other fields of human enquiry. Cabanis's younger contemporary, Xavier Bichat, shared this reluctance to transfer quantitative methods, so useful for the study of the physical universe, into the domain of the living and the dying. Earlier, Diderot had deflated contemporary enthusiasm for mechanical or mathematical models when he explored the implications of the temporal dimension of the organic order, and later, more systematically, Claude Bernard would finally formulate the theoretical bases for experimental medicine which respected the unique character of organic phenomena without renouncing for medicine the determinism he admired so much in the physical sciences. In fact, his passionate appeal for a strict determinism forced him to de-emphasize statistical methods, for he firmly believed that as long as medicine relied on such tools it would remain a conjectural science. Reluctant to linger with ambiguity, Bernard shunned the probabilistic quality of statistical statements and urged physicians and physiologists to identify precise causes for specific effects. Laplace, his mentor and inspiration, had led the way in this search for a rigorous determinism in the physical sciences. A half-century later Bernard exhibited that same passion for exactitude, but strangely enough he ignored Laplace's own considerable attention to problems which required the calculus of probabilities, a method of conjecture yielding only probability statements on the matter under study. 


\section{Medical knowledge and statistical methods in early nineteenth-century France}

In fact, the popularity of the calculus of probabilities, as much a consequence of Condorcet's efforts to apply it to civic questions as of Laplace's own work, had positive effects on the medical community where physicians speculated on its utility for estimating the veracity of medical judgments.

Condemned by some, praised by others, and misunderstood by many, the calculus of probabilities and, more generally, the application of quantitative methods in medicine had a stormy history in the first half of the nineteenth century. Examining the arguments of advocates and opponents of numerical methods will offer a better understanding of the profession's response to specific aspects of Enlightenment thought and also clarify the process by which medicine was adapted to a secular and scientific age. ${ }^{1}$

\section{STATISTICS AND THE CALCULUS OF PROBABILITIES: THE HISTORICAL CONTEXT}

Throughout the first half of the nineteenth century, the analysis of statistical data received the attention of administrators, political economists, public health officers, and finally physicians. Reminiscent of de Witte's, Petty's, and Bacon's appeal for a natural history of man, vital statistics assisted leaders in their estimation of the state's strengths and weaknesses. Founded with this end in mind, the Sociéte Royale de Médecine (1776) had gathered information for a medical topography of the kingdom, a necessary first step in evaluating the effect of seasonal or climatic changes on the well-being of rural France. Later, in 1800 , the Bureau de Statistiques was an ill-fated attempt at a more systematic study of the realm's human and material resources. Although short-lived, both initiatives indicated the growing interest in obtaining a more precise, less impressionistic picture of national life. In $1817 \mathrm{Chabrol}$, the Prefect of Paris, ordered the regular publication of statistics, which admirably fulfilled the administrator's desire for reliable information on birth and mortality rates, the movement of grains, meats, and other foods. In the same spirit public health boards and individual physicians, such as Louis Villermé or Parent-Duchâtelet, systematized the collection of public health records and data on occupational illnesses or mortality. These studies flourished in the 1820s and 1830s, extending into the domain of epidemiology and eventually creating what came to be known as moral statistics. Taken together they provide a portrait of France adjusting to the burdens of urbanization and early industrialization. Often the doctor eloquently defended the victims of modernization, by evoking, statistics in hand, the inequality of the rich and the poor before death. Active also in the countryside, as Balzac's realistic characterization

\footnotetext{
${ }^{1}$ I am grateful to reviewers for their helpful editorial and bibliographical suggestions. See Erwin H. Ackerknecht, Medicine in the Paris hospital, 1794-1848, Baltimore, Md., Johns Hopkins Press, 1967; and Edouard-Rudolf Müllener, "Zur methodischen therapeutisch-klinischen Forschung der "École de Paris" (1800-1850)', Gesnerus, 1966, 23: 122-131.

See also Michael J. Cullen, The statistical movement in early Victorian Britain. The foundations of empirical social research, Brighton, Sussex, Harvester Press, 1975: Ian Hacking. The emergence of probability. A philosophical study of early ideas about probability, induction, and statistical inferences, Cambridge University Press, 1975; Ulrich Tröhler, 'Quantification in British medicine and surgery 1750-1830, with special reference to its introduction into therapeutics', Ph.D. thesis, University College London, 1978.
} 


\section{Terence D. Murphy}

suggests, the physician frequently embodied the secular and humanitarian spirit of Enlightenment France. This sentiment reached its climax in 1848 when concerned physicians called for the instauration of social medicine, an attempt to convert the doctor and the profession into the advocate and defender of the labouring classes before the civil authorities. These concrete gestures carried into practice an essential Enlightenment theme: science as public knowledge would be a force for reform and renovation. Put differently, reformers believed that open discussion of relevant information could move men to correct social injustices and further material progress.

A related development in mathematics would also influence doctors seeking an objective measure of confidence in medical judgments. Aside from public discussion of pertinent information, a second cause animated eighteenth-century reformers. In rejecting the arbitrary exercise of personal powers, so characteristic of the ancien régime, they called for rational action in a democratic society. Their problem, of course, was to fix on just or rational objectives at a time when passion and pride conditioned political choice. Above all, they had to suggest how it was possible to arrive at wise decisions when competing interests and personal loyalties conditioned decisions made through democratic processes. In other words, the reformers had to demonstrate that a just society could emerge from the decisions of the majority. In Ars conjectandi (1713) Jacob Bernouilli had suggested a way out of the dilemma: perfect the calculus of probabilities to a point where errors in human judgment could be estimated with a high degree of precision. An astute mathematician could then develop the rules for evaluating human judgment and thus offer the possibility of rational organization in the political domain. This early suggestion for a science of decision-making influenced Condorcet, who eventually took the bold, perhaps impetuous step towards applying the calculus of probabilities to social and political life. It was this initiative which subsequently inspired physicians to wonder about its applications to medical judgments. In his Essay on the application of mathematics to the theory of decision making (1785), Condorcet's most sophisticated mathematical undertaking, he attempted to set down the rules for calculating the plurality necessary to assure the veracity of decisions affecting a variety of civic values and matters of criminal justice. Formerly, probability theory had proven its worth in estimating life annuities or rates of maritime insurance. Now, Condorcet argued, calculation could also serve in an entirely different domain, the operations of the human mind, "where it weighs the grounds for belief and calculates the probable truth of testimony or decisions". ${ }^{2}$ Contemporary events, controlled by passion and factionalism, proved the need for such a guide. Though never completed, Condorcet's social mathematics remained a part of his legacy to social theorists and, as we shall see, influenced a significant portion of the medical profession.

In 1795, just a year after Condorcet's death, Pierre-Simon de Laplace, one of the founding fathers of probability theory and the foremost physicist of his day, delivered a series of lectures at the École Normale. In the tenth and final presentation Laplace

\footnotetext{
2 Marie-Jean-Antoine-Nicolas Caritat, marquis de Condorcet, 'A general view of the science of social mathematics (1793)', in Keith M. Baker (editor), Condorcet: selected writings, Indianapolis, Bobbs Merrill, 1976, p. 186. See K. M. Baker, Condorcet: from natural philosophy to social mathematics, Chicago and London, University of Chicago Press, 1975, pp. 330-342.
} 


\section{Medical knowledge and statistical methods in early nineteenth-century France}

chose to discuss the calculus of probabilities, a lecture which later served as the basis of his well-known Essais philosophiques sur les probabilites. To understand the larger context of the subsequent debate over mathematical methods in medical science, it is necessary to pay close attention to Laplace's argument.

In his lecture Laplace described how the calculus of probabilities had originated as a response to problems posed in games of chance. He then proceeded to trace its gradual extension to the physical and moral sciences. Here Laplace reaffirmed Condorcet's optimism, demonstrating that the slow progress to master the physical and moral sciences derived only from human ignorance of the causes of events and not from the nature of the subject studied. The knowledge of causes, then, was the preeminent problem. Contemporary developments had shown that it was possible to reason from the frequency of events to the probability of their causes. In other words, the repeated experience of a set of relations could lead to conclusions about their constancy and regularity. Laplace pointed out that this method was extremely useful for seeking out the fixed relations in seemingly variable events. With this aid, for example, mathematicians could calculate the probability of birth rates or mortality rates from statistical data. But Laplace expressed reservations about the utility of applying mathematics to decisions taken by an assembly. The fundamental drawback of such procedures, he remarked, lies in the inescapable fact that varying degrees of intelligence and disinterestedness characterize the members of an assembly. As long as passion and self-interest affect a representative's vote, it is useless to seek out the probable truth of decisions through the use of the calculus. In fact, the more vital the issue, the more likely are vested interests to counter the voice of reason. Yet his scepticism about current possibilities did not rule out hope for the future use of the calculus.

Before men could take such a step, Laplace argued in the conclusion of his presentation, it was extremely important that all people be educated. Yet even this was not enough. To secure the play of reason on civic life, Laplace willingly took a step back from Condorcet's democratic ideals when he insisted that only an élite of just and enlightened men should act as national representatives. Reminiscent of Plato's philosopher ruler, Laplace's representative would assure the administration of justice and safeguard the state from illusions thrown up by popular passion or prejudice. Ideals would also guide his decisions: "Truth, justice, humanity, these are the eternal laws of the social order which must rest solely on the true relations between men and on man's relation to nature; they are as necessary to man as the law of universal gravity is to the physical order."3 But unlike the Platonic sage, Laplace's lawmaker admitted he had never penetrated beyond the world of shadows. Consequently contingency and uncertainty continued to mar human progress towards the ideals of truth and justice. In spite of the difficulties, Laplace recommended a way out: The observation and analysis of the facts of political economy would provide better insight into the operations of the social order, revealing its injustices and flaws. Above all, lawmakers had to avoid any adherence to traditional assumptions and practices, for only if men

\footnotetext{
${ }^{3}$ Pierre-Simon de Laplace, Exposition du système du monde, Paris, J. B. M. Duprat, an VII, p. 351.
} 


\section{Terence D. Murphy}

scrutinized economic relations as they had the physical world could human affairs take on a semblance of order.

If Laplace gave only qualified approval to Condorcet's initiatives to apply the calculus to the decisions taken by a plurality of votes, he was more enthusiatic about another project: the estimation of the plurality necessary for condemnation in criminal trials. In fact, among all the political projects which later occupied Laplace this particular one concerned him the most. In analysing it he had no difficulty in seconding Condorcet's efforts. The reason for his enthusiasm is perhaps the distinction separating the matter before the jury from the problem confronting the legislators. Whereas a lawmaking assembly often had to chart a course for future public action, the jury evaluated the facts of a past event. In other words, the legislator frequently intervened to correct abuses or reorient policy towards more appropriate social goals. This endeavour obviously involved a large degree of doubt as did any attempt to create the conditions for a healthy and just political environment. Jurors, on the contrary, were not concerned with what laws should govern the public realm, but only with the supposed infraction of existing laws. Their judgment, then, bore only on matters of fact and not on social values.

After Laplace's forceful demonstration, the utility of the calculus of probabilities for the physical sciences was beyond question. Could a similar application resolve outstanding medical problems? From within the profession a few, but influential voices responded affirmatively. Charles-Louis Dumas, director of the Montpellier medical school, stands among the most prominent supporters of this new but untried methodology. "The analysis of combinations", he wrote, "has already been applied with success to different aspects of the physical and moral knowledge of man. If the same method is used for other subjects, it is possible that one day physiological and medical questions will be illuminated to such a high degree that most men will acknowledge the results as they do the demonstrative truths of the most exact sciences". This declaration of faith testified to the ardent desire to measure medical science against the same epistemological standards measuring degrees of truth and error in the physical sciences. Not all physicians, however, subscribed to this thesis.

Pierre-Jean-Georges Cabanis, a member of the last generation of philosophers known as the ideologues, hesitated to adopt the epistemological standards of the physical sciences for medical matters. In Degré de certitude de médecine (1788), a treatise written just before the Revolution, Cabanis defended the medical arts against sceptics. In the context of the Enlightenment's admiration for rational and experimental science, several critics objected to the less rigorous epistemological standards of medicine. In a nuanced response, Cabanis took the offensive, accusing the detractors of the art of having a narrow and incorrect view of medical knowledge. Prejudicing the issue, he added that these critics were probably mere theoreticians or incompetent practitioners. "The latter, seeing that their medicine does not succeed and feeling that it is vague and without any basis, refuse to believe that a genuine medical science can exist whose rules would be well-founded and whose practice truly

\footnotetext{
4Charles-Louis Dumas, Discours sur les progrès futurs de la science de l'homme, Montpellier, Tournel, an XII, p. 29.
} 


\section{Medical knowledge and statistical methods in early nineteenth-century France}

useful." Furthermore, the search after useful knowledge need not follow the path opened by mathematics. In medicine, Cabanis continued, such precision is unwarranted. Only a "plausible certitude" is required in the choice of remedies. A more exacting standard, while suitable to the speculative demands of the spirit, would immobilize men rather than aid them in the daily tasks of practical life. Cabanis justified this transposition of medicine on to a plane with the contingent truths of temporal existence by arguing that "each science has its own kind of proofs", a formulation that ran counter to Cartesian aspirations but which echoed more realistic appraisals of current possibilities. In this position he joined forces with Condorcet and Laplace, who had suggested that the moral or human sciences, like the other sciences of observation, could offer a "high degree of probability" for their conclusions and thus serve as guides to action in cases of practical necessity. ${ }^{5}$ Cabanis, however, refrained from suggesting that any particular method of calculation be applied to the medical sciences. Instead he asserted that specific epistemological limits circumscribed the field of medical knowledge, just as they defined the boundaries of the social sciences. Going beyond Condorcet's cautious and exacting method for evaluating a particular course of action, Cabanis located the seat of medical judgment "in a happy instinct ...", "in the sensation of the artist". ${ }^{6}$ In a word, the observer and practitioner acquired through experience an ability to weigh correctly the consequences of remedies on the course of an illness. This non-quantifiable talent, a kind of sympathie morale, allowed the doctor to identify with his patient, to read the signs of sickness and suggest a way to modify their effects. This highly personalized, almost intuitive approach to medical practice was firmly grounded on Condillac's sensationalist psychology and, at the same time, claimed to occupy the same epistemological ground as Condorcet's probabilist science of man. While the application of these themes to medicine clearly attached Cabanis to the Enlightenment tradition, a contemporary, Philippe Pinel, had a different understanding of this heritage. ${ }^{7}$

A distinguished humanitarian and untiring scholar, Pinel has earned praise for his work in Parisian asylums as well as for his attempt to classify diseases. His advocacy of institutional reforms links him to predecessors who favoured improved medical attention for marginal groups in French society. Such a course of action, reformers acknowledged, was incumbent on an enlightened nation now responsible for its citizens. And his efforts to organize the many characteristics of illness placed him among those naturalists, like Linnaeus or Lavoisier, who had carried out systematic classifications in other domains. These endeavours derived from a Baconian passion to know and to order nature after some comprehensible pattern useful to men. To these themes of the Enlightenment, Pinel added yet another concern, the evaluation of medical judgments by an objective standard. Here again the example of other sciences moved Pinel to implement a more rigorous standard for the validity of medical

\footnotetext{
'Pierre-Jean-Georges Cabanis, 'Du degré de certitude de la médecine', Oeuvres philosophiques de Cabanis, Paris, Presses Universitaires de France, 1956, 2 vols., vol. 1, p. 90, and 'Rapports du physique et du moral', ibid., vol. 1, p. 110, note 1 .

'Ibid., vol. 1, p.91. See also Martin Staum, Cabanis. Enlightenment and medical philosophy in the French Revolution, Princeton University Press, 1980.

${ }^{7}$ Müllener, op. cit., note I above, p. 122.
} 


\section{Terence D. Murphy}

practice. Experimental evidence, the hallmark of scientific knowledge, had to have greater force in medical conclusions. Unfortunately, rivals claimed success by citing examples favourable to their cause, but for an "experiment to carry weight and to serve as a solid basis for treating [the ill], it has to be made on a large number of patients ...". To strengthen his argument, Pinel, like Cabanis before him, turned to the probability theory and its utility for testing the accuracy of conclusions. "It is enough to say that it [experimental medicine] must be founded on the theory of probabilities already so successfully applied to several aspects of civil life, and if the methods for treating the sick are to have a solid foundation, they must henceforth rely on the theory of probabilities". The reason for such insistence is found in the slow progress of the therapeutic arts which, until now, "contain only vague precepts whose application is perhaps more difficult and more uncertain than a total lack of knowledge". Repeated observation of the sick, regular recording of findings, comparison of data over time - these habits alone could form the basis of a sound therapeutics. Slowly Pinel's recommendations, already adopted by some colleagues, became accepted practice in hospitals and taken as a whole came to be known as clinical medicine.

In sum, Pinel saw two sides to medical science. The first, represented in his own systematic nosography of diseases, was a natural history or complete description of sicknesses. The second, related to evaluating a course of medical intervention, was embodied in therapeutics. The former, he declared, "is already well-advanced... taking as its guide the path followed in all the other branches of natural history". The latter still struggled against a "blind empiricism which prevents medicine from acquiring the character of a true science, an achievement it will only attain through the application of the calculus of probabilities". ${ }^{10}$ Note that Pinel's reference to the calculus was a loose, non-mathematical illusion. Practical limitations, such as a wide dissimilarity of case histories, restricted the application of quantitative evaluations and diminished their significance. Moreover, clinical medicine never fully adopted the rigorous standards of statistical testing as required by the calculus. Instead practitioners like Pinel had to content themselves with comparing the limited number of cases at their disposal and arriving at a judgment, based on simple proportions, as to the success or failure of a particular therapy. What should be underscored, however, is the firm conviction that therapeutics and medicine in general could only claim to share in the contemporary understanding of science if their conclusions rested on firmer ground than the physician's intuition. In a word, physicians did find it important to measure medicine against the epistemological standards of the other sciences. But if the comparison proved momentarily embarrassing, they believed that developments in the social sciences, specifically Condorcet's social mathematics, offered a model of scientific truth appropriate to medical problems.

Medical journals and dictionaries reinforced these forthright statements on the role

3 Philippe Pinel, 'Résultats d'observations et construction des tables pour servir à déterminer le degré de probabilité de la guérison des aliénés ( 9 février 1807)', Mémoires de la classe des sciences mathématiques et physiques de l'Institut national de France, 1807, 8: 169.

Ibid., p. 170.

10 Ibid. 


\section{Medical knowledge and statistical methods in early nineteenth-century France}

of mathematics in medicine. In the introduction to the Dictionnaire des sciences médicales, Etienne Pariset wrote: "Having examined the patient and noted the various symptoms the results lead the doctor by a calculus of probabilities, or rather by a very refined sentiment and by a sort of instinct superior to reason, to an appropriate choice of remedies and a well regulated method of treatment". ${ }^{11}$ When Laplace reconsidered this issue in 1814, he was more precise. Although he wrote that "the theory of probabilities is fundamentally only good sense reduced to calculation", he carefully submitted intuitive judgments to the rigours of analysis, something lacking in Pariset's comment. ${ }^{12}$ This was necessary because knowledge of therapeutic agents and their effects was extremely limited. Even then a crucial question remained: how many observations were necessary to demonstrate the superiority of one agent over another? "It is here that the role of the calculus of probabilities becomes indispensable". ${ }^{13}$ And with specific attention to therapeutics, Laplace wrote: "The calculus of probabilities can make us appreciate the advantages and inconveniences of the methods employed in the conjectural sciences. Thus, in order to recognize the best treatment in healing an illness it suffices to try each of them on the same number of patients while keeping all the circumstances perfectly alike. The superiority of the most advantageous treatment will be manifested more and more as the number of cases increases; and the calculus will make known the probability corresponding to its [the treatment's] advantage". ${ }^{14}$ In this passage Laplace set down two requirements. First, the doctor had to have a sufficient number of cases to judge the beneficial effects of various treatments. Determining that number was, for the moment, beyond the doctor's competence, and Laplace himself never directly applied the calculus to medical phenomena. The second requirement, a constant relation between observed effects, imposed demands that would trouble physicians. While all contemporaries agreed that observation and complete description was the basis of a sound therapeutics, it remained an open question whether numerical methods could actually influence the choice of a remedy in a particular case. Frequent failures had tempered physicians' enthusiasm for new solutions to persistent problems, and not all saw the imposition of numerical standards as the answer to their difficulties. Auguste-Charles Savary, a contributor to the Dictionnaire des sciences médicales, sounded a note of caution. He admitted, of course, that past experience conditioned present judgments and, hence, that analogical reasoning provided the basis for all prognostics. But he warned doctors against assuming any identity between individual cases, something possible in mathematics but unattainable in medicine: "Analogy in medicine is never as perfect as it is in the mathematical sciences. In effect in mathematics there is an equality of relations, whereas in medicine there is only similarity, resemblance, approximation. Accordingly, analogy, and other influences effecting the character of a disease must be taken into account". 13

\footnotetext{
${ }^{11}$ Etienne Pariset, 'Prospectus', Dictionnaire des sciences médicales, Paris, Panck oucke, 1812-1822, 58 vols., vol. 1, p. vii.

12 Pierre-Simon de Laplace, Essais philosophiques sur les probabilités, Paris, Courcier, 1814, p. 95.

13 Ibid., p. 50.

14 Ibid., p. 51.

${ }^{15}$ Auguste-Charles Savary, 'Analogie', Dictionnaire des sciences médicales, op. cit., note 11 above, vol. 2 , p. 18 .
} 


\section{Terence D. Murphy}

THE NUMERICAL METHOD: ADVOCATES AND CRITICS

The preoccupation with individual differences troubled physicians, who believed that the absence of demonstrable principles deprived medicine of a permanent base and gave them free reign in the selection and administration of remedies. In the 1820s, Louis, Chomel, and others waged an ardent campaign to win acceptance of a numerical method for evaluating the worth of particular treatments. They had numerous obstacles to overcome and in the end they could not convert the profession to their way of thinking. Colleagues' reluctance to accept their point of view was not, however, a rejection of empirical standards: on the contrary, many practitioners felt that the kind of generalization required by the new method was itself a flight from objectivity. Louis argued against this point of view which gave pre-eminence to the individual case. He insisted that physicians "could gather together similar facts in order to enunciate laws which experience constantly verifies.... Experience also shows... that the same medication administered to individuals differing in age, strength, temperament, etc. . . could have a nearly constant success". ${ }^{16}$ Fortified with these principles, Louis concluded that "facts need not have a perfect resemblance in order to be grouped". Similarly, "when the action of a therapeutic agent is very efficacious it seems to efface numerous differences and to act directly on the disease itself'. ${ }^{17}$ This was a reasonable argument that merited attention. But Louis used this methodological argument to challenge the therapeutic value of bleeding, a traditional remedy popularized by Broussais, a noted physician of the Val-de-Grâce. The issue was joined when Louis used the numerical method, which was no more than a proportional statement of success or failure out of the total treated, to suggest that repeated purgations cured more patients than any other remedy, particularly Broussais's.

Opposition to Louis came from two groups. First, those who disagreed with his methodology could argue that this procedure emulated the experimental sciences but lacked their rigour. Others simply saw no firm evidence, numerical or otherwise, for abandoning a particular remedy in favour of another. Here Louis was on weak ground, for by his own count many patients failed to benefit from his treatment. More importantly, he had not devised a test for significance which would indicate conclusively success or failure in the competition between rival treatments. For some physicians the very admission that patients succumbed to a particular therapy showed that Louis's margin of error was still too large. In a word, no decisive evidence appeared to convince physicians of the value of a particular remedy. In fact, there was considerable ambiguity concerning the very nature of such evidence. Despite the opposition, a persuasive group argued that medicine should follow the lead of the moral and physical sciences in adopting numerical or statistical methods, for these techniques had come to represent the forward edge of social and scientific improvement. A partisan of this point of view stated the case clearly: "Statistics have been of

\footnotetext{
${ }^{16}$ Pierre-Charles-Alexandre Louis, Recherches sur les effets de la saignée dans quelques maladies inflammatoires et sur l'action de l'émétique et des vésicatoires dans la pneumonie, Paris, J. B. Baillière, 1835 , pp. 72-73.

17 Ibid., p. 74.
} 


\section{Medical knowledge and statistical methods in early nineteenth-century France}

immense utility, powerfully serve the cause of progress, give a new impetus to political economy and impose on public hygiene a totally new character of exactitude and rigour. Is it possible that statistics should stop precisely on the threshold of medicine? that it be applicable to the duration of life, but not to the sick; that it serve to calculate the chances of life and death of the population in all social conditions, but be unable to calculate the chances of life and death of the population of hospitals?' 18 Less rhetorical but more to the point were the questions: "But what are the limits to the applications of the calculus in pathology and therapeutics, and what degree of confidence can we accord to the results that it gives?"'19

During the 1830s a vigorous exchange between these rival points of view animated the medical profession when the Academy of Sciences and the Academy of Medicine debated the role of probability theory in the medical sciences. The nature of medical knowledge remained at the centre of these discussions as participants reflected on the proper epistemological boundaries of their science. An unusual aspect of these proceedings appears in Simon-Denis Poisson's initial rejection of the application of the calculus of probabilities to problems of medical choice. Later he was to reverse this stance and side with those favouring such a usage. Another important feature of this debate touched on the social role of the doctor, which several believed would be severely modified should the calculus affect medical judgment. From these heated exchanges also came the clarification of the two aspects of medical statistics, the first pertaining to medical topography or public health questions and the other related to therapeutics. If many doctors viewed this latter usage with suspicion, there was general approval for statistical studies of populations. Persuaded to accept the conclusions of statistical analysis for matters related to public health, doctors would not give their assent to mathematical guidelines where the individual patient was concerned. A strong humanist tradition which honoured personality and uniqueness partially explains this reluctance to submit the sick to a statistical order. A desire to protect the profession and strengthen its feeble hold on society could also have directed those hostile to an inversion of the decision-making process in therapeutics.

Medical statistics, willingly provided by certain doctors, already gave civil authorities the powerful tool to regulate matters of public behaviour affecting the community's health. In other words the doctor's knowledge and skill made him the perfect collaborator ready to assist public officials' attempts to regulate disorder. In fact, the public health movement, built on medical statistics, increased the political power acquired by the medical profession as the progress of industrialization necessitated their intervention to criticize or justify changes in the organization of social life. But co-operation with authorities was not the sole explanation for the profession's increasing share of local power, for the prestige accorded to the talented doctor also enhanced the socio-political position of the group. Primarily acquired through private practice and not public function, this esteem derived from the ability to discern and treat the illnesses of the sick. To mitigate the importance of the doctor's

\footnotetext{
${ }^{18}$ Casimir Broussais, De la statistique appliquée à la pathologie et à la thérapeutique, Paris, Baillière, 1840, pp. 14-15.

19 Ibid., p. 14.
} 


\section{Terence D. Murphy}

insight into the causes of disorders might disenchant the patient and reduce the medical act to a mere mechanical intervention. In the 1830 s these and other issues came under scrutiny during the debates on the efficacy of medical statistics.

\section{THE DEBATE: THE ACADEMY OF SCIENCES AND THE ACADEMY OF MEDICINE}

In the Academy of Sciences the debate began when François Double, recently elected to the section of medicine and surgery, issued the report on the merits of Civiale's Recherches statistiques.... Poisson, the renowned mathematician and member of the commission, concurrently was developing his law of large numbers, an extension of Condorcet's and Laplace's work on probability theory. When the commission's report appeared on 5 October 1835, it disapproved of any application of the calculus to medical problems. No evidence is available to indicate that Poisson chose at that time to disagree with Double, the commission's reporter. This omission later encouraged members of the Academy of Medicine to claim that Poisson opposed the application of probability theory to therapeutics. During the debate, Poisson would clarify the position which was fully developed in his Recherches sur la probabilite des jugements principalement en matière criminelle, which was finally published in $1837 .{ }^{20}$

Double's principal objection to statistical analysis came from the suppression of individual differences required by the method: "In statistical matters . . . the first care before all else is to ignore that a man is an isolated individual and only to consider him as a fraction of the species. It is necessary to strip him of his individuality in order to eliminate any accidental qualities from the question. In applied medicine, on the contrary, the problem is always individual, the facts only presenting themselves one at a time ... and finally it is only a single man with all his idiosyncracies that the doctor must treat. The masses remain completely out of the question". ${ }^{21}$ Double also noted that the calculus of probabilities calls for "an unlimited number of facts.... Everything is different in the medical order; the facts are too few to enter into the domain of the calculus of probabilities". ${ }^{22}$ Obviously Double was correct in asserting that large numbers were indispensable to formulate correct judgments. The next question, unasked by Double, was how large they had to be. In concluding, he refused any concession to the numerists or sceptics who challenged medical truth. Did medical knowledge suffer from a lack of certitude because it was unable to meet the rigorous demands of the calculus? Here Double insisted on the validity of Morgagni's maxim: Non numerandae sed perpendendae observationes (it is not necessary to count, but it is necessary to weigh the facts). The calculus, not permitting this kind of selection, was inapplicable to medicine. This tentative judgment did not satisfy the advocates of statistical methods, and soon thereafter they would have an opportunity to defend their views before the Academy of Medicine.

A report on the treatment of typhoid by purgation precipitated this debate. Louis, Andral, and Bouillaud, all defenders of the numerical method, participated in the

\footnotetext{
${ }^{20}$ I am grateful to Père Constabel of the Centre Alexandre Koyré for his advice on Poisson's development during this period.

${ }^{21}$ C. r. hebd. Séanc. Acad. Sci., Paris, 21 September 1835, 1: 173

22 Ibid., p. 174.
} 


\section{Medical knowledge and statistical methods in early nineteenth-century France}

commission which evaluated this study purporting to demonstrate the superiority of repeated purgations over bleeding in the treatment of typhoid fever. This challenge to popular practice had a rather unsettling effect on the Academy, especially as it relied on quantitative comparisons as evidence for its claims. The commission, sensitive to the feeling of the prominent defenders of bleeding as a treatment, cautioned against undue speculation and recommended the continued evaluation of the new remedy: "Before this treatment can be adopted as the best in all cases, ... it is necessary to follow these observations over several years and in several different countries". ${ }^{23}$ Only then could this result be transformed into a law of therapeutics. Premature application of the numerical method distorts the results, but properly applied it serves as the final judge. Some members did not share the commission's enthusiasm and asked the Academy to enquire into the utility of statistics in its application to medicine.

A month later, in April 1837, the debate opened when Risueno d'Amador, already well known for his work in pathological anatomy, discussed the application of mathematics to medicine. ${ }^{24}$ An informed but unkind observer characterized the ensuing debate in this way: "At a time when the confused noise of a thousand opposed voices reigned in the medical world, you could only be heard by speaking a little bit louder. At a time when so many opposing parties vied for the empire of science, you could not win adherents without exciting them". ${ }^{25}$ The medical press, delighted by Risueno d'Amador's flamboyant oratory as much as his unbridled attack on the supporters of the calculus, reported the presentation and covered the subsequent debate which lasted three months, from April to July 1837.

In his opening discourse Risueno d'Amador held that medicine enjoyed a privileged place among the arts and sciences. Alternately relying on the deductive method or analogous reasoning to define medical enquiry, he paraded medicine under the banner of science, claiming that such methods led to truths appropriate to the subject. Viewing medicine as an art, he noted that in the final stage of the medical act the independent judgment of the doctor-artist intervened to bridge the gap between these scientific conclusions and the choice of treatment. This last step was accomplished by the intuitive genius, a special instinct which only the well-trained and gifted doctor possessed. Understood in its two-fold nature, the defence of medicine against the calculus, became a struggle against the intrusion of abject scepticism and blind routine. Risueno d'Amador argued that in offering only probable truths the calculus abandoned science to doubt. The Academy's acceptance of such conclusions indicated that the results of the debate carried on throughout the scientific revolution on the nature of scientific knowledge had never penetrated the medical community, or at least were not perceived as applicable to medicine. In brief, that previous debate had declared the Cartesian formula and method for scientific discovery inappropriate to

${ }^{23}$ Bull. Acad. Méd., Paris, 14 March 1837, 1: 498.

24 Benigno Juan Isidor Risueno d'Amador was born on 13 February 1802 in Cartagena, Spain. He was educated at Montpellier and reinterpreted certain themes of vitalism for a nineteenth-century audience. See Adolph C. P. Callisen, Medicinisches Schriftsteller-Lexicon der jetzt lebenden Aerzte, Wundärzte . . ., Copenhagen, beim Verfasser, 1830-1845, 33 vols., vol. 16, p. 145, and vol. 31, p. 471.

${ }_{25}$ Jean-Baptiste Bouillaud, Essai sur la philosophie médicale et sur les généralités de la clinique médicale, Paris, Baillière, 1837, p. xi. 


\section{Terence D. Murphy}

the world outside the realm of clear and distinct ideas. Probability statements were the best and only alternative to scepticism. This admission, while taking a more modest epistemological position, had established the basis for the calculus as a scientific tool.

Risueno d'A mador disagreed, maintaining that the calculus substituted "a uniform, blind and mechanical routine for the action of the spirit and individual genius of the artist". Unsuited to the twin nature of medicine, the calculus also posed moral problems: "Your starting-point forbids any application of this research to individuals, for the problem of the numerist is not to heal a particular patient, but to heal the most possible on a determined number. This problem is essentially anti-medical" ${ }^{26}$ In concluding Risueno d'Amador generalized his critique of the calculus. Not only did such a tool fail to serve medical science, it could not guide decisions in any of the moral sciences, where choice "was the result of a spontaneous, instinctive conviction". He compared this movement of the mind to the moral determination of a jury "formed much more by the real value of witnesses than by their number". ${ }^{27}$

Poisson worked steadily during that year to disprove just such assertions. A little more than a month after the debate, he published his Recherches sur la probabilite des jugements en matière criminelle et en matiere civile. In several places he referred to the errors and distortions of recent discussions evaluating the use of the calculus. First, he noted that Laplace's ideas "have been misinterpreted; and people have too hastily concluded that mathematical analysis is not applicable to this kind of question [criminal judgment], nor generally to subjects that one calls morals. This is a prejudice that I have unfortunately seen shared by good minds, and in order to destroy it, I believe it is useful to recall a few general considerations...". ${ }^{28}$ Most specifically Poisson asserted that probability theory could be used in therapeutics and went on to demonstrate its range and limitations: "In applying, for example, this general proposition to therapeutics, the corollary, which is moreover conformable to simple good sense, is that if a medication has been successfully employed in a very large number of similar cases, and the number of cases where it has not succeeded is very small compared to the total number of cases of this experiment, it is very probable that the medication will succeed in a new trial". ${ }^{29}$

In this particular debate, however, a supposedly objective method had led to opposite conclusions. What then is the worth of the method? Later, an astute commentator would respond that any purely numerical method could easily fall victim to the predispositions of an observer, an occurrence not unknown in the history of science. "There is one indispensable condition for the validity of statistical results and that is the morality of the observer, his good faith, his intelligence. Good faith is necessary for facts have been invented or falsified in the past. And intelligence is required, for not every man has the quality to affirm the value of a fact." Unfortunately, there are far too many physicians who must be asked: "What right have you to see? What right have you to believe what you have seen? Who told you

${ }^{26}$ Bull. Acad. Méd., Paris, 1836, 1: 635.

27 Ibid., p. 668.

28 Simon-Denis Poisson, Recherches sur les probabilités des jugements en matière civile, Paris, Bachelier, 1837 , p. 7.

${ }^{29}$ Ibid., pp. v-vi, note 1 . 
that you have seen?"'30 These are blunt but important questions which reveal a sensitivity to a perennial problem in the history of discovery: that fact has a way of mingling with the predispositions of the observer. In an age when medical science had only a rudimentary understanding of the nature of disease, it is not surprising that men adhered, often desperately, to theories or practices, however unsettling the results. At least their doctrines gave coherence to their world and guided medical discussion and research as it entered a more empirical age.

Even if the majority of doctors objected to the numerical methods, they recognized the advantages of statistical considerations in the area of public health. Louis Castel, Louis's opponent, thought the time appropriate for distinguishing between medical statistics and the numerical method: "Called in turn medical statistics and numerical method, we have been given by this procedure two faces, as a fantastic being of mythology and have been shown at first one face and then the other. I would not dispute the place of statistics in medicine. It measures the influence of place, climate, the seasons, age, temperament, previous sicknesses, professional activity on the patients". ${ }^{31}$ This kind of approbation did not extend to the numerical method which Castel judged an arid calculation precisely because it often was not based on discrete or significant data. The central focus of this debate for Castel concerned the collection and evaluation of information gathered by doctors. The lack of homogeneity, an evident failing in Louis's data, called into question his conclusions, whereas the information gathered by the public health services or administration was a large enough sample of similar facts to proceed to an accurate correlation between environment and health.

Even Castel's distinction between the two methods and support for medical statistics in matters of public health was not accepted by Risueno d'Amador. For him a fundamental law required a fixed equilibrium between births and deaths, between the healthy and the sick. Human efforts notwithstanding, nature's balance would continue to rule over government planning or the solicitude of those who argued that clean cities and safe industries would preserve large numbers from early death. Taking an example of human intervention in nature's course, he questioned the effectiveness of vaccination, long proclaimed as the solution to smallpox, saying that it had not actually lowered the national mortality rate. At the time this was a questionable and unprovable conclusion but one shared by many of his colleagues who believed, as he, "that death had need of nourishment; she goes elsewhere to find it when doors are closed on one side". Pushing his generalization Risueno d'Amador continued: "Nobody would doubt that vaccine saves the lives of certain individuals, healing according to individual signs; but never and in no instance can a doctor judge the utility of his art by the results of large numbers. Nature preserves the species, art prolongs the individual life as long as it can". ${ }^{32}$

Malthus had a similar explanation for the mortality rate. But there is no need to stop at Malthus in seeking predecessors for Risueno d'Amador's view, for the English

\footnotetext{
${ }^{30}$ Broussais, op. cit., note 18 above, p. 44.

${ }^{31}$ Bull. Acad. Méd., Paris, 1837, 2: 768.

32 Ibid., p. 804.
} 


\section{Terence D. Murphy}

economist restated in another form the attitude towards death of an older, more familiar tradition. In the eighteenth century many naturalists and students of the life sciences, including doctors with a penchant for philosophical speculation, adhered to a form of vitalism which assumed a rigorous balance between the forces of life and death. As in other debates, this view of nature ceded no ground to mechanical metaphors. Above all, the vitalist philosophy tried, often unsuccessfully, to avoid the kind of reductionism too familiar in mechanical explanations of organic processes. Nor was the mathematician's method of studying the physical world appreciated or valued. His abstraction from physical realities ignored the individuality so respected and so necessary to vitalist explanations of the relations between natural beings.

Only at the level of the species did the vitalist philosopher agree to the mechanical and mathematical metaphors. There was a balance, an equality between the forces of life and death. Human intervention never truly affected this pre-established harmony which rigorously bound men to a routine imitating the cycle of the seasons. The optimism of the secular philosophers, their notion of progress, their belief in the powers of human reason and the perfectibility of human nature - all these were alien to the sober stoicism of natural philosophers who accepted tragedy as a necessary part of the human condition. Their metaphors, phrased in terms of birth and death, understood nature as the commencement and gradual fulfilment of a particular destiny, a special plan or pre-conceived design. Their discussion of the struggle between the forces of life and death only echoed the mythical combats between good and evil, a dialectical situation which issued forth in a higher form of opposition while never eliminating the tension governing nature's ontogeny.

This world view thoroughly assimilated human relations and their history into a totally naturalistic system of explanation. Conveniently enough, the vitalist tradition had denied Cartesian dualism and located human endeavours, whether rational or otherwise, in the course of nature's history, eliminating any special place or distinct field for human activity. Consequently, this mode of explanation had no need to explore the possibility of a science for man. Lacking a well-defined, independent subject, a genuine science of man could not exist within the limits of this tradition, and medicine, tied to these assumptions, concentrated on the individual's well-being, leaving the collectivity to nature's rigorous law. The art of healing, understood in these terms, was not and could not be a social science.

The 1837 debate closed on a negative note, leaving the opponents and advocates of numerical methods bickering with each other. Confusion and vendetta, always present during the debate, were cleared away on only one essential point. Medical statistics, indispensable for the public hygienist, took its proper place in the vocabulary of doctors, being distinguished from the numerical method, a procedure that rarely convinced only because therapeutics was so much in need of appropriate remedies. When these appeared, the numerical method could convincingly demonstrate their value. Throughout the sixty years which separated the founding of the Sociéte Royale de Médecine from this debate the medical profession tested accepted doctrine with empirical standards, but never fully submitted to the rules of order governing other sciences. Some doctors believed this reserve weakened medical science. Others praised such independence. Despite this divergence, the medical community had matured 
during this formative period. Through intelligent use of its corporate influence, the profession had safeguarded the country from mesmerism and the democratization of health care. After these developments the question of who would decide on matters of medical choice was clear. Only when Louis confronted the profession with his numerical method did the medical community discuss how competent medical judgments were formed. And here the issue was not the preference of one remedy over another, for competing treatments left patients equally disarmed against cholera and other fevers. The central point in this debate revolved around the conception of medicine and its relation to the other sciences. Its traditional methodology, empirical and inductive, certainly played a role in the physical sciences, but mathematics, the corner-stone of modern science, made few inroads into a discipline built on the union of anatomy and physiology.

\section{EPILOGUE}

The most prominent commentator who later reflected on the application of mathematics to medicine was Claude Bernard, the vigorous defender of experimental methods in physiology and their extension to medicine. An examination of his thoughts, which strongly influenced subsequent attitudes, can serve as a useful epilogue to this discussion, for his essay on experimental medicine recapitulates earlier theoretical debate on the nature of medical knowledge.

First, Bernard considered the nature and limitations of our knowledge of the physical and biological orders. Distinctly different from the abstract or purely mental quality of mathematical propositions, knowledge of the natural world measured our understanding of the conditions which produce specific effects. Unlike the transposition of our own concepts, the essence of mathematical reasoning, the physical and biological sciences undertook to uncover the unfailing consistency of nature itself. Experimentation with the natural order, whether in physics, chemistry, or physiology, yielded the results which allowed men to determine or foresee the consequences of particular effects. Concerned in establishing a common ground for all the natural sciences, Bernard objected to those, like Risueno d'Amador, who would reserve a special domain for the organic or medical sciences. The notions of life, death, health, and sickness he considered as antiquated remnants of a pre-scientific mentality. Physiological functions and their degrees of performance were the only building blocks of medicine. What mattered, then, was a thorough understanding of the equilibrium of an organism and the modes of change introduced by pathological or therapeutic agents. What was important, of course, was to note exactly how a particular agent modified the functioning of a system. In the absence of this kind of knowledge, medical science was still insufficient for the doctor's needs. In a word, Bernard advocated a rigorous understanding of the human organism and of the conditions of existence that perpetuated its stable and regular growth.

A strict determinism was the hallmark of his experimental medicine. For this reason he minimized the importance of quantitative work, which he felt was premature, given the limits of medical knowledge. It was more important, he argued, to study the process of respiration than to quantify the volume of air in the lungs. And 


\section{Terence D. Murphy}

given the cyclical nature of organic phenomena, it is wrong to try to conclude anything significant from the mere taking of averages. Statistical measures were equally unsatisfying. Knowing that a particular surgical method led to a mortality of $2 / 5$ signified "absolutely nothing scientifically and provides no certain basis for a new operation, for you do not know if this new case will be among the cured or among the dead". Bernard's approach was much more fruitful: "Instead of empirically collecting facts, study them ... in their special determinism. It is necessary to examine the fatal cases with great care, trying to discover the cause of mortal accidents .... So that, if you know the exact cause of success or failure, you will always be able to succeed in any particular cases .... Only then will you have attained scientific determinism. But you will never achieve this with the aid of statistics, for statistics have never taught nor will they ever teach us anything about the nature of phenomena". Nor will they tell the physician how to treat a particular case. ${ }^{33}$

In his conclusions, Bernard stood back from the long and quarrelsome debate over the applicability of mathematics to medicine to reflect on the possibilities for progress in the medical sciences. Early proponents of the application of statistical methods to medical practice had argued that the Enlightenment ideology of empirical study and objective standards had to penetrate medical science before it could reach maturity. In their absence, practitioners could always rely on traditional remedies of questionable value, defending their choice by appeal to some higher sensitivity or gifted intuition. Quarrels between defenders of rival practices could never be settled unless an unambiguous test could decide the question. While these arguments, framed in terms of a scientific age, persuaded some, many physicians were reluctant to credit statistical data with real significance. Claude Bernard was among them, but his objections carried in them a clear defence of scientific determinism, the only firm grounding for medical science. Statistics, he argued, could suggest a probable outcome but never a certitude, and in specific cases certitude or absolute determination was precisely what the physician needed. Otherwise medicine would remain a conjectural art and the doctor an artist who responds to the indeterminism of particular cases with his own genius or medical tact. In his view, those who defended statistics as the basis for medical decision-making actually weakened the scientific tenor of those decisions, giving free play to the imagination of practitioners. ${ }^{34}$ The problem, of course, was not the exclusion of statistics from medical science, but their judicious use as a research tool. In the end the debate over the place of mathematics in medicine served as a focal point for discussion of the relation of medical knowledge to the epistemological standards of the other sciences, and, above all, to measure the utility of new techniques against the humanist concerns of the practitioners.

\section{SUMMARY}

In the early nineteenth century a persuasive and varied group of physicians urged the profession to consider the utility of numerical methods for medical practice. They

\footnotetext{
${ }^{33}$ Claude Bernard, Introduction à l'étude de la médecine expérimentale, Paris, Flammarion, 1952, p. 192.

34 Ibid., pp. 191-196.
} 
were convinced that medical knowledge would rest on firmer foundations if practitioners employed methods that had served the physical sciences so well. Echoing Condorcet's hopeful but perhaps illusory aim, some doctors believed that questions of human judgment, whether social or medical, could ultimately be decided through analytic procedures which would convince rational men of their validity and veracity. This position affirmed that an unambiguous numerical method could decide questions of therapeutic choice. More modest proposals, less threatening to the traditional perception of the doctor's unique role in the medical act, restricted the application of numerical techniques to epidemiology. Yet even here the extensive use of the methodology fortified a more intense concern for questions related to the public's health and, by extension, tended to de-emphasize accepted views of the physician's concern for individual patients. Opposition came from diverse sectors of the profession. Many articulate physicians contested the claims for objectivity advanced by the advocates of numerical methods. In fact, a strong empirical tendency fortified critics who argued against generalization based on a precise number of cases. The variety and complexity of the human subject defied any movement towards uniform treatment of the sick, who ultimately could only receive adequate aid from the talented and perceptive physician. In the 1830s rivals clashed in the Academy of Medicine and in the Academy of Sciences. Both debates provided ample testimony to the divisions in professional opinion concerning the appropriate methodology for evaluating medical judgments. Later, Claude Bernard advanced an explicit objection to statistical methods which, in his view, only deterred the physician from the search for the specific cause of a particular effect. Strict determinism alone could provide the kind of certitude that medical science required. The many-sided debate focused attention on the methods and objectives of medicine and promoted further reflection on the access to useful knowledge at a time when the profession confronted medical and social problems which defied easy solution. 